\title{
Flexible bronchoscopy contribution in the approach of diagnosis and treatment of children's respiratory diseases: the experience of a unique pediatric unit in Tunisia.
}

\author{
Samia Hamouda, Amal Oueslati, Imen Belhadj, Fatma Khalsi, Faten Tinsa, Khadija Boussetta
}

Bechir Hamza Children's Hospital of Tunis, Department B

\begin{abstract}
Objective: Our study aimed at assessing the role of flexible bronchoscopy (FB) in improving diagnosis and management of children's respiratory conditions in the pediatric unit of FB, newly created and unique in Tunisia.

Methods: Retrospective study including all the FB achieved in our pediatric unit from 2009 to 2014.

Results: We performed 365 FB in 333 patients aged 46 months on average (1 month - 15 years), often under conscious anesthesia (81.6\%). FB was performed for diagnostic purposes in 341 cases and for therapeutic purposes in 24 cases. Eight anatomical abnormalities were revealed in 22 patients. An intraluminal bronchial obstruction was found in $71 \mathrm{FB}$, mainly due to a foreign body $(n=36)$. A vascular anomaly was responsible for nine cases out of 17 extraluminal obstructions. Airways malacia was observed in $60 \mathrm{FB}$. Bronchoalveolar lavage was performed in 196 cases. It was determinant in $43.9 \%$ of the cases. FB was of great diagnostic value in $74.8 \%$ of the cases. It influenced the management of the patients in $58 \%$ of the cases. The FB for therapeutic purposes was beneficial in all cases. Few complications occurred (5.5\%).

Conclusion: FB is a safe tool providing precious diagnostic and/or therapeutic help for the clinician.

Keywords: Flexible bronchoscopy, child, bronchoalveolar lavage, foreign body aspiration, pulmonary alveolar proteinosis. DOI: http://dx.doi.org/10.4314/ahs.v16i1.7

Cite as: Hamouda S, Oueslati A, Belhadj I, Khalsi F, Tinsa F, Boussetta K. Flexible bronchoscopy contribution in the approach of diagnosis and treatment of children's respiratory diseases: the experience of a unique pediatric unit in Tunisia. Afri Health Sci. 2016;16(1): 51-60. bttp:/ / dx.doi.org/10.4314/ahs.v16i1.7
\end{abstract}

\section{Introduction}

Pediatric pulmonology has experienced significant progress in recent decades in the understanding and management of respiratory diseases of children, becoming a specialty in itself. The development of diagnostic tools, including flexible bronchoscopy (FB), has contributed much to the development of this specialty.

In adults, FB, used since 1967, has allowed a safer diagnostic approach and is more informative than rigid bronchoscopy. Thanks to the miniaturization of devices, in 1978, Wood ${ }^{1}$ was able to describe a flexible endoscope prototype for pediatric use. With innovations in the field of fiber optics, this instrument has evolved to enable the exploration of the bronchial tree by video endoscopy at any age, even in preterm infants.

\section{Corresponding author: \\ Hamouda Samia \\ Bechir Hamza Children's Hospital of Tunis, \\ Department B \\ Email: samia.hamouda@gmail.com}

At present, the indications for FB have widened, making it an inevitable tool in pediatric pulmonology. It is indicated for a diagnostic or therapeutic purpose. FB allows direct exploration of the bronchial tree and provides information about its anatomy and the existence of a possible intrinsic or extrinsic obstacle on the airway. It helps in the diagnosis of dynamic abnormalities such as malacia, undiagnosed by rigid bronchoscopy ${ }^{2}$.

It also allows the realization of some samples, the bronchoalveolar lavage (BAL) in particular. The BAL is considered as a key exam in various conditions such as chronic interstitial lung diseases. FB also helps in the treatment of some pathologies such as a foreign body granuloma by cryotherapy, or pulmonary alveolar proteinosis (PAP) by a therapeutic BAL ${ }^{3,4}$.

In Tunisia, for several years, FB in children was carried out in adult pulmonology departments. In January 2009, a pediatric bronchoscopy unit was created in the children's hospital of Tunis. Our study aimed at assessing the FB role in improving diagnosis and the management of children's respiratory conditions in this unit through the analysis of the FB indications, its results, and its complications. 


\section{Material and methods}

\section{Study design}

Our study was retrospective covering a period of six years from January 2009 to December 2014. It enrolled all FB performed at the FB unit in the Children's Hospital of Tunis. We included all patients who had this exam regardless of the original department, FB indication and its outcome. Patients who had not undergone FB because they had one of those contraindications: severe hypoxemia, unstable hemodynamics, cardiac arrhythmia, an active massive hemoptysis, or bleeding disorders, were excluded.

\section{Flexible bronchoscopy procedure}

To make an FB procedure, a general protocol was followed. First, before each FB, the exam was explained to the parents and /or the child. Oral consent was obtained. Six hours fasting was required before the $\mathrm{FB}$ and two after. FB could be performed in the bronchoscopy unit, an intensive care unit (ICU), or in a surgical operating room. The choice depended on the FB indication and the patient's clinical condition. Small fiberoptic bronchoscope (Table 1) (outer diameter of $3.4 \mathrm{~mm}$ to $3.8 \mathrm{~mm}$ ) was used for patients under ten.

Table 1: The used flexible bronchoscopes

\begin{tabular}{|c|c|c|c|c|}
\hline \multirow{2}{*}{ Manufacturer } & \multicolumn{3}{|c|}{ Fiber bronchoscopes } & \multirow{2}{*}{$\begin{array}{c}\text { Video- } \\
\text { bronchoscopes } \\
\text { BF-Q180 } \\
\text { BF-3C160 }\end{array}$} \\
\hline & $\begin{array}{l}\text { Storz11001 } \\
\text { Storz11002 }\end{array}$ & Pentax FB-10V & $B F-P E 2$ & \\
\hline Outer diameter & $\begin{array}{c}5 \mathrm{~mm} \\
3.7 \mathrm{~mm}\end{array}$ & $3.4 \mathrm{~mm}$ & $4.9 \mathrm{~mm}$ & $\begin{array}{l}5.5 \mathrm{~mm} \\
3.8 \mathrm{~mm}\end{array}$ \\
\hline Channel inner diameter & $1.5 \mathrm{~mm}$ & $1.2 \mathrm{~mm}$ & $2.2 \mathrm{~mm}$ & $\begin{array}{c}2 \mathrm{~mm} \\
1.2 \mathrm{~mm}\end{array}$ \\
\hline Bending (up/down) & $180^{\circ} / 120^{\circ}$ & $180^{\circ} / 130^{\circ}$ & $180^{\circ} / 130^{\circ}$ & $80^{\circ} / 130^{\circ}$ \\
\hline
\end{tabular}

For older patients, fiberoptic bronchoscopes with an outer diameter between $4.9 \mathrm{~mm}$ and $5.5 \mathrm{~mm}$ were used. The bronchoscopes were sterilized automatically before and after each use. All FB were undertaken by the same pediatric pulmonologist trained in bronchoscopy. Pulse oximetry monitoring was assured systematically during the FB.

In the bronchoscopy unit, $\mathrm{N}_{2} \mathrm{O}$ inhalation (50\%) and intravenous midazolam (dosage: $0.1 \mathrm{mg} / \mathrm{kg}$ ) were ap- plied. No anesthesia was administered in infants aged under six months. In an ICU or in an operating room, conscious or general anesthesia was provided by the intensivist. General anesthesia was induced with propofol $(3 \mathrm{mg} / \mathrm{kg})$ and fentanyl $(3 \mu \mathrm{g} / \mathrm{kg})$; then, the patient received propofol $(10 \mathrm{mg} / \mathrm{kg})$. In all cases, local anesthesia based on idocaine was administered in the nose $(2 \%)$, larynx, trachea and bronchi $(1 \%)$.

After crossing the upper airway, a careful exploration of the tracheobronchial tree was made. Then, sampling 
was performed according to the $\mathrm{FB}$ indication and the endoscopic findings. It consisted of a BAL, ciliary brushing, and/or bronchial biopsy. The BAL was achieved at a lobar or segmental orifice. It was based on an injection of three physiological saline samples of 1 $\mathrm{ml} / \mathrm{kg}$ followed by a gentle sucking after each instillation. The collected liquid was sent for microbiological and/or histological study.

Therapeutic BAL always occurred in an operating room under general anesthesia. In a single lung, all lobes were successively treated with a total volume equal to 150 $\mathrm{ml} / \mathrm{kg}$ of physiological saline held at $37^{\circ} \mathrm{C}$. The aspiration was made by fractions of 20 to $50 \mathrm{ml}$.

Methylene blue test was indicated when esophageal-tracheal fistula (ETF) was suspected. The substance was introduced in the esophagus through a gastric tube progressively, retrograde and simultaneously to an endoscopic trachea and hull exploration.

The fibro-aspiration consisted in unblocking airways facilitated, if needed, by the instillation of a few saline milliliters in situ.

\section{Data collection}

Data collection was based on FB reports. Each report included the patient's age, the original department and the FB indication. The details of the FB implementa- tion, its outcome and complications were also recorded. The result of the specimens was noted for each patient. The contribution of the FB was evaluated from medical files data.

\section{Statistical analysis}

Our study was cross-sectional and descriptive. The data was entered using Excel software as qualitative values and numbers with an expression as a percentage. The statistical results were presented as percentages, tables and/or diagrams. The association between variables was searched using the Chi square test. The significance level of "p" was 0.05 .

\section{Results}

We carried out 365 FB in 333 patients. The mean activity was $61 \mathrm{FB}$ per year. The FB was performed under conscious anesthesia in $81.6 \%$ of the cases. It took place in the endoscopy room $(85.5 \%)$, in an ICU $(9.9 \%)$ and in a surgical operating room (4.6\%). The $333 \mathrm{pa}-$ tients were divided into 199 boys and 134 girls (sex ratio $=1.4$ ), and aged three years and ten months on average [range, 1 month; 15 years]. Patients were aged under two years in $57.9 \%$ of the cases (Figure 1). Eighteen patients had more than one FB mainly for the assessment of specific treatment efficiency $(n=9)$ and for therapeutic BAL $(n=2)$.

Figure 1: Age profile of our population

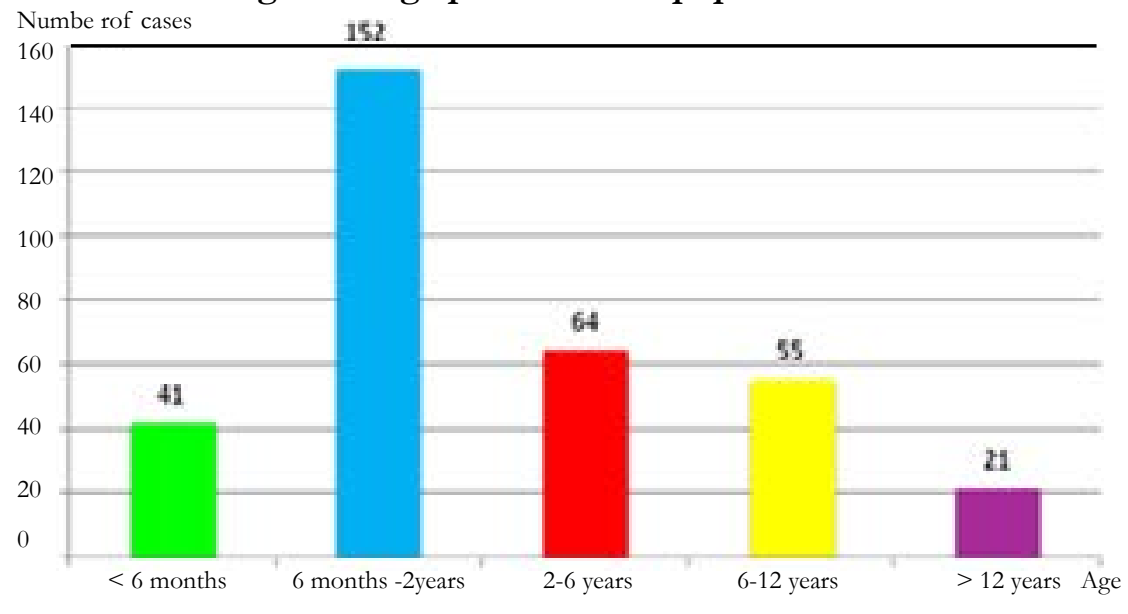


FB was performed for diagnostic purposes in 341 cases (93.4\%). The first indication was a suspicion of foreign body aspiration $(\mathrm{n}=77$ ) (Figure 2 ). Twenty-four FB
$(6.6 \%)$ were performed for therapeutic purposes. Expected tasks were a mucus plug aspiration in ventilated patients $(\mathrm{n}=9)$, a therapeutic BAL $(\mathrm{n}=9)$, and a difficult intubation $(\mathrm{n}=6)$.

Figure 2: Flexible bronchoscopy indications for diagnostic purposes $(n=341)$
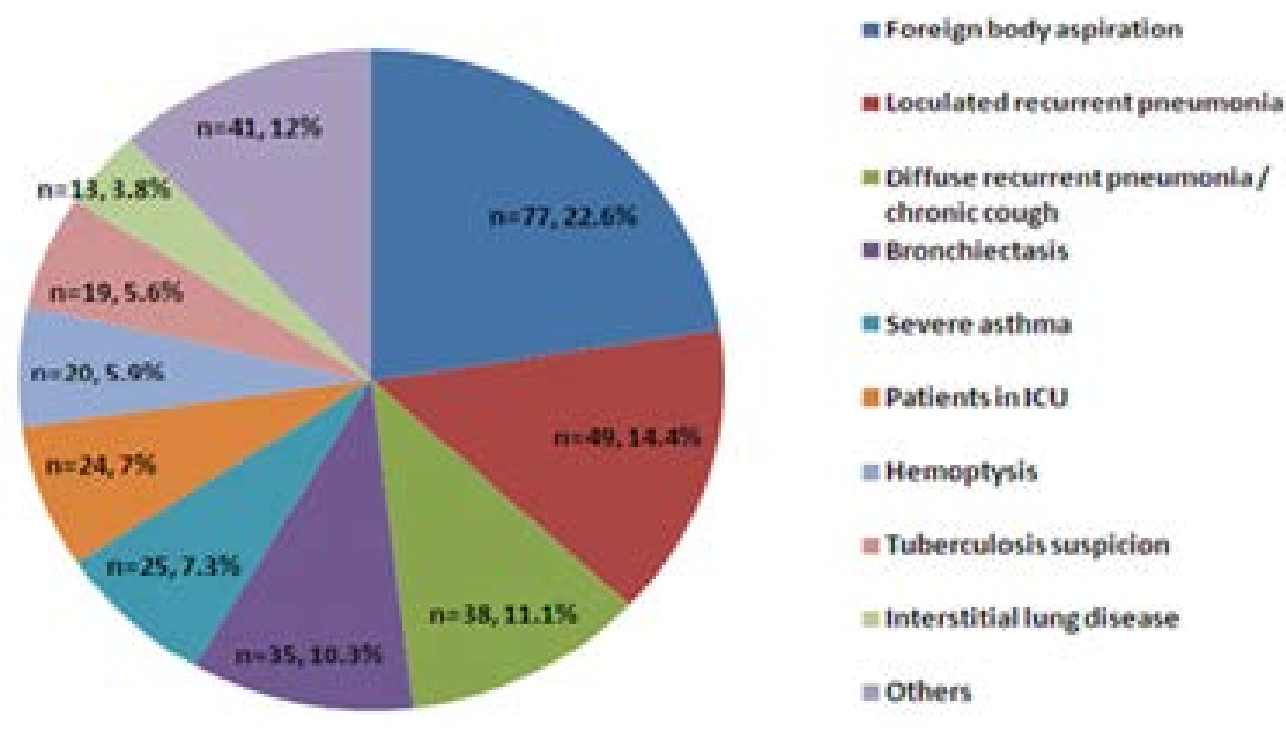

Twenty-two patients had morphological abnormalities consisting in bronchial stenosis $(\mathrm{n}=5)$, lung hypoplasia or agenesis $(n=5)$, isomerism or situs inversus $(n=4)$, bronchial tree distortion ( $\mathrm{n}=4$ ), tracheal bronchus ( $\mathrm{n}$ $=3)$, and tear of the vocal cord $(n=1)$. An intrinsic air- way obstruction was observed in $71 \mathrm{FB}(19.4 \%)$. It was mostly left $(\mathrm{n}=44,62 \%)$, not crossable $(\mathrm{n}=51,72 \%)$, and mainly due to a foreign body $(n=36)$. A carcinoid tumor was revealed in one patient and a plastic bronchitis in two (Figure 3).

Figure 3: Specific endobronchial abnormalities revealed by flexible bronchoscopy: (a) non crossable obstacle in the intermediate bronchus related to a foreign body, (b) carcinoid tumor in the left main bronchus, (c) plastic bronchitis in the left main bronchus, (d) esophageal-tracheal fistula facing the carina
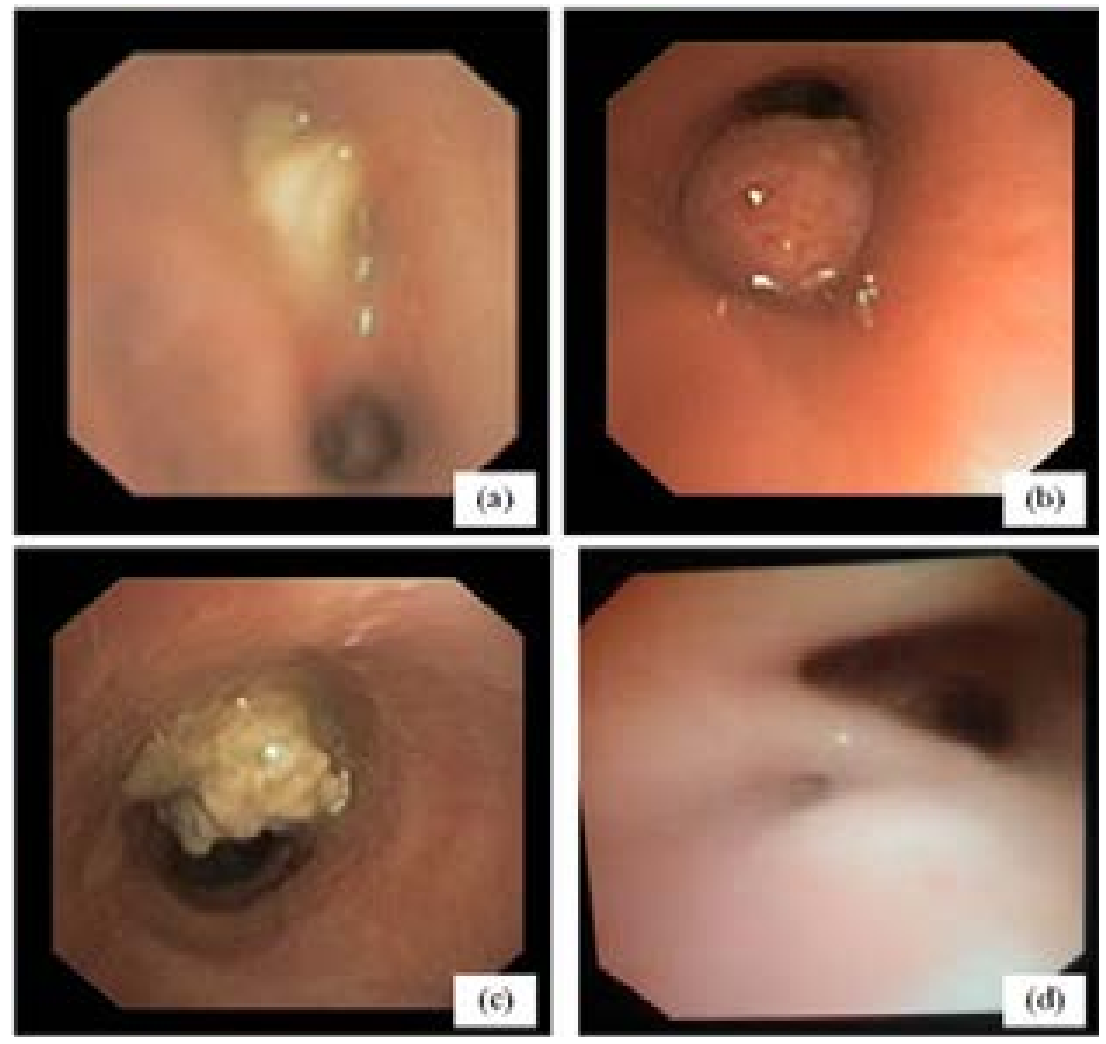
Extrinsic compression was found in $17 \mathrm{FB}$ (4.6\%). It was crossable in all the cases, and particularly related to a vascular anomaly $(\mathrm{n}=9)$. Airway dyskinesia was objectified in $60 \mathrm{FB}(16.4 \%)$. Tracheomalacia was the most often reported $(n=52)$ and was most often moderate $(n=20)$ (Table 2$)$.

Table 2: Malacia and intrinsic and extrinsic airways obstructions revealed by flexible bronchoscopy

\begin{tabular}{|c|c|c|c|c|c|c|c|}
\hline \multicolumn{2}{|c|}{ Intrinsic airways obstruction } & \multicolumn{2}{|c|}{ Extrinsic airways obstruction } & \multicolumn{4}{|c|}{ Malacia } \\
\hline Type of obstacle & $\begin{array}{c}\text { Number } \\
\text { of FB }\end{array}$ & $\begin{array}{c}\text { Type of obstacle } \\
\text { (confirmed by CT scan) }\end{array}$ & $\begin{array}{c}\text { Number } \\
\text { of FB }\end{array}$ & Location & Mild & Moderate & Severe \\
\hline Foreign body & 36 & Aortic arch abnormalities & 5 & Larynx & 4 & 11 & 2 \\
\hline Plastic bronchitis & 10 & $\begin{array}{l}\text { Mediastinal lymphadenitis related } \\
\text { to: }\end{array}$ & 5 & Trachea & 17 & 20 & 15 \\
\hline Tuberculosis caseum & 7 & - Tuberculosis & 3 & $\begin{array}{l}\text { Bronchu } \\
\mathrm{s}\end{array}$ & 4 & 7 & 4 \\
\hline Mucus plugs & 6 & - $\quad$ Sarcoidosis & 1 & & & & \\
\hline $\begin{array}{l}\text { Granuloma after foreign body } \\
\text { expulsion or extraction }\end{array}$ & 4 & - $\quad$ Severe pulmonary infection & 1 & & & & \\
\hline Sarcoidosis granuloma & 4 & $\begin{array}{l}\text { Dilated pulmonary artery caused by } \\
\text { pulmonary hypertension }\end{array}$ & 4 & & & & \\
\hline Tuberculosis granuloma & 1 & Mediastinal mass & 2 & & & & \\
\hline Carcinoid tumor & 1 & Esophageal mass & 1 & & & & \\
\hline $\begin{array}{l}\text { Multiple small granuloma in } \\
\text { a severe case of thoracic } \\
\text { trauma }\end{array}$ & 1 & & & & & & \\
\hline $\begin{array}{l}\text { Granuloma with unknown } \\
\text { origin }\end{array}$ & 1 & & & & & & \\
\hline Total & 71 & Total & 17 & Total & 25 & 38 & 21 \\
\hline
\end{tabular}

Bronchial inflammation was noted in 204 cases (55.9\%). It was diffuse and bilateral in 156 cases $(76.5 \%)$. It was mild, moderate or severe in respectively 114 (55.9\%), $84(41.2 \%)$ and six $(2.9 \%)$ cases. Significant bronchial secretions were present in 180 cases (49.3\%). They were clear in 137 cases $(76.1 \%)$ and purulent in 43 cases $(23.9 \%)$.
BAL achieving, therapeutic BAL excluded, depended on FB indications, bronchial secretions characteristics in situ and FB tolerance. Among the $341 \mathrm{FB}$ performed for diagnostic purposes, $196 \mathrm{BAL}$ took place. They were mostly motivated by recurrent pulmonary infections (RPI) (29\%) (Figure 4). 
Figure 4: Bronchoalveolar lavage indications for diagnostic purposes $(n=196)$
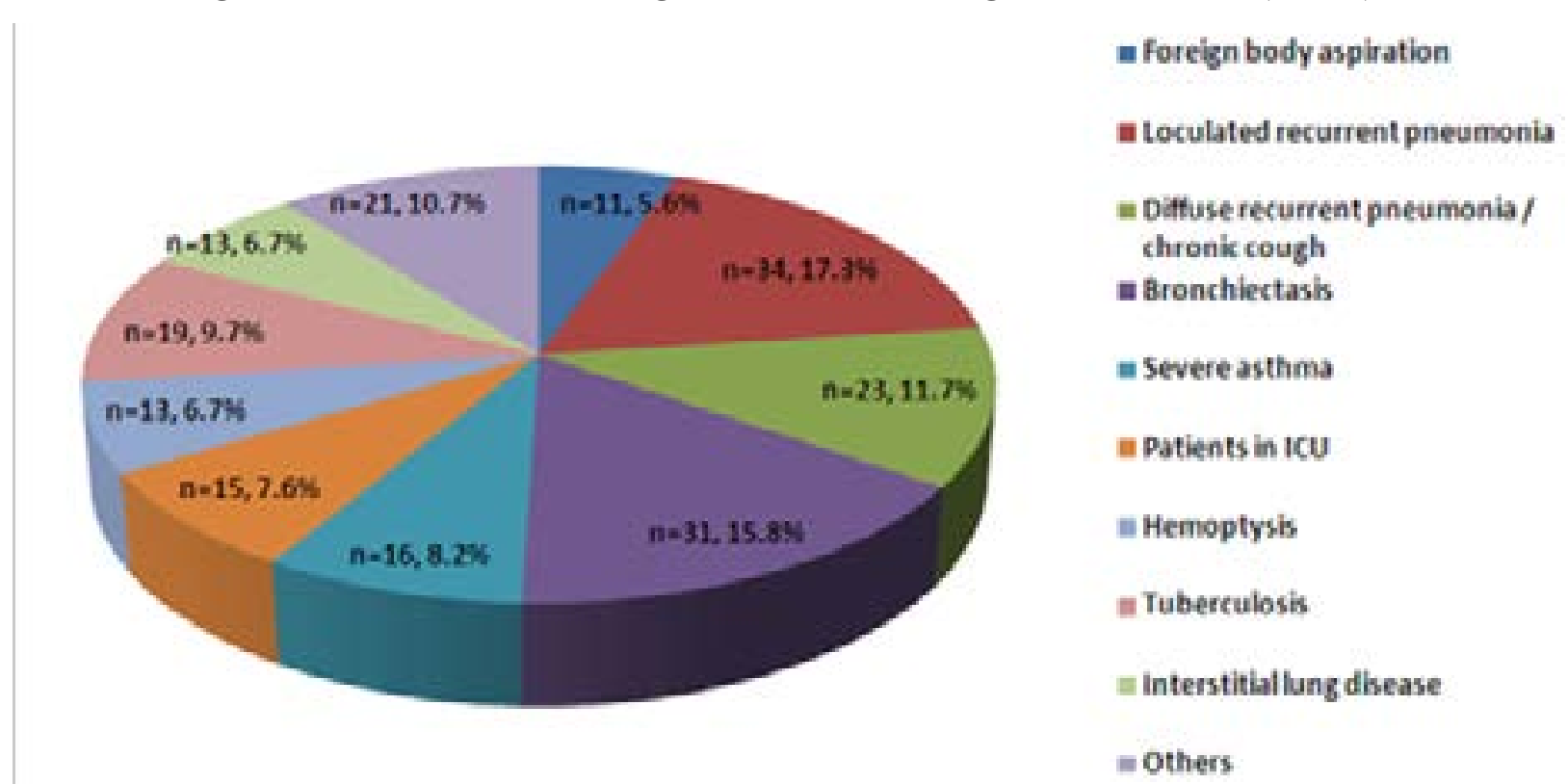

nothers

The BAL was systematic for suspected pulmonary tu- lus influenzae being the major one $(\mathrm{n}=25)$. The BAL berculosis $(\mathrm{n}=19)$, and interstitial lung diseases ( $\mathrm{n}=$ led to Mycobacterium tuberculosis isolation in five cas13). BAL microbiological analysis, performed in 161 es of suspected pulmonary tuberculosis out of 19 and cases, showed germs in $35.4 \%$ of the cases, Haemophi- in two bronchiectasis cases (Table 3).

Table 3: Bronchoalveolar lavage microbiological findings

\begin{tabular}{l|c}
\multicolumn{1}{c|}{ Isolated microorganisms } & Number of cases \\
\hline Haemophilus influenzae & 25 \\
Haemophilus parainfluenzae & 9 \\
Mycobacterium tuberculosis & 7 \\
Streptococcus pneumoniae & 6 \\
Branhamella catarrhalis & 5 \\
Staphylococcus aureus & 1 \\
Klebsiella pneumoniae & 1 \\
Virus Respiratoire Syncytial & 1 \\
Cyto-Mégalo Virus & 1 \\
Bocavirus & 1 \\
No pathogens & 104 \\
Total & $\mathbf{1 6 1}$ \\
\hline
\end{tabular}


Positive BAL culture (Mycobacterium tuberculosis excluded) was mostly noted in "RPI" and "bronchiectasis" groups (64\%). No association was found between positive BAL culture and inflammation or purulent mucus aspect. BAL cytology was essential to etiological diagnosis in $27 \%$ of the cases (19/70) (Table 4, Figure 5).

Table 4: Bronchoalveolar lavage cytology findings

\begin{tabular}{|c|c|c|c|}
\hline $\begin{array}{l}\text { Number } \\
\text { of cases }\end{array}$ & Flexible bronchoscopy indication & Bronchoalveolar lavage cytologg findings & $\begin{array}{c}\text { Final diagnosis } \\
\text { considering clinical and } \\
\text { paraclinical patient data }\end{array}$ \\
\hline \multirow[t]{3}{*}{7} & $\begin{array}{l}\text { Congenital intersititial lung } \\
\text { disease }\end{array}$ & $\begin{array}{l}\text { Milky bronchoalveolar lavage (Figure 5) } \\
\text { Numerous spumous macrophages with positive periodic acid } \\
\text { Schiff(PAS) coloration deposits }\end{array}$ & Pulmonaryalveolar proteinosis \\
\hline & 4 & $\begin{array}{l}\text { Hypercellularity with nomal formula }(\mathrm{n}=2) \text { or elevated } \\
\text { neutrophils rate (27\% on average) }(\mathrm{n}=2) \\
\text { Absenceof positive PAS coloration }\end{array}$ & $\begin{array}{l}\text { Congenital suffactant protein } \\
\text { deficiency (SPC and ABC3) } \\
\text { (confirmed by lung biopsy) }\end{array}$ \\
\hline & 1 & Hypercellularity with elevated neutrophils rate(27\%) & $\begin{array}{l}\text { Pulmonary and digestive } \\
\text { lymphangiectasis }\end{array}$ \\
\hline 5 & Diffuse recurrent pneumonia & Numerous spumous macrophages colored with "red oil" & Aspiration \\
\hline 3 & Sarcoidosis suspicion & $\begin{array}{l}\text { Lymphocytic alveolitis (mean lymphocyte rate = 26\%) } \\
(C D 4+/ C D 8+=2,2 \text { in one patient) }\end{array}$ & Sarcoidosis \\
\hline 2 & $\begin{array}{ll}\text { Hemoptysis } \quad(\mathrm{n}=1) \\
\text { / Diffuserecurrent } \\
\text { pneumonia }\end{array}$ & $\begin{array}{l}\text { Hemorrhagic aspect of the bronchoalveolar lavage (Figure 5) } \\
\text { High Golde score (120 and 130) }\end{array}$ & $\begin{array}{l}\text { Idiopathic pulmonary } \\
\text { hemosiderosis }\end{array}$ \\
\hline 2 & $\begin{array}{l}\text { Tuberculosissuspicion }(\mathrm{n}=1) \\
\begin{array}{ll}\text { /Lungnodules } & (\mathrm{n}=1)\end{array}\end{array}$ & Normal formula with positive CDla cells $>1 \%)$ & Langerhanshistiocytosis \\
\hline
\end{tabular}

Figure 5: Bronchoalveolar lavage aspect in specific conditions: (a) hemorrhagic aspect in pulmonary hemosiderosis, (b) milky appearance in pulmonary alveolar proteinosis, (c) therapeutic bronchoalveolar lavage liquid and its aspect after sedimentation (d)

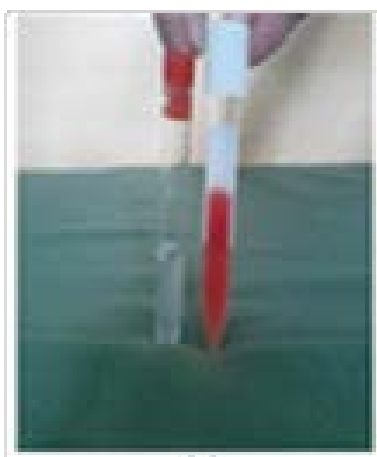

(a)

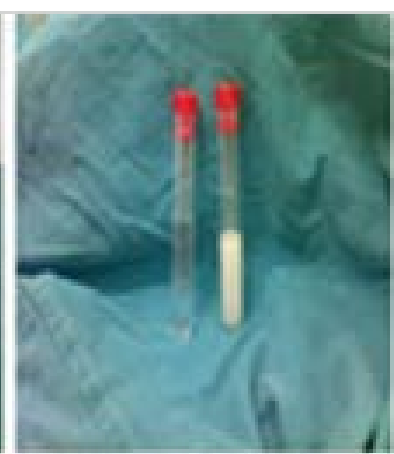

(b)

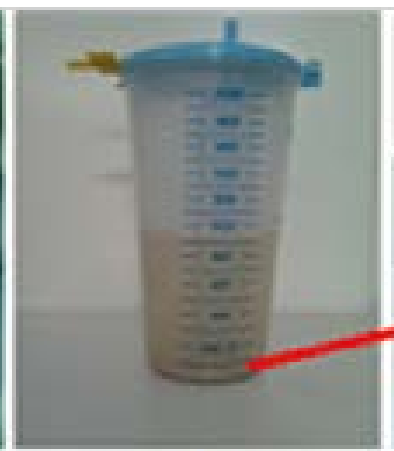

(c)

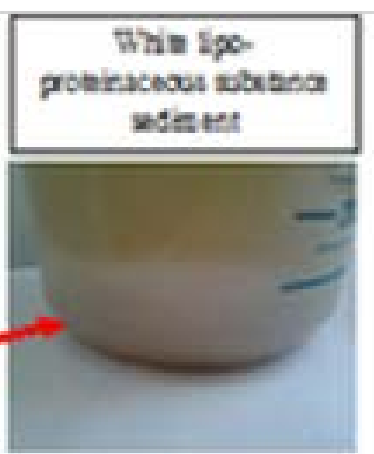

(d) 
Methylene blue test $(n=8)$ concluded to a permeable ETF in half the cases (Figure 3). Bronchial brushing was performed in 31 cases. The specimens have been on examination by an electronic microscope. No results have been available yet.

Among the $24 \mathrm{FB}$ realized for therapeutic purposes, the intubation succeeded in all cases $(n=6)$. The mucus plug aspiration was achieved in six cases. The FB rectified the assumption of bronchial mucus plug by objectifying an extrinsic compression in two cases and a severe malacia in one case. A complete clinical remission was obtained after four therapeutic BAL (Figure 5), spaced three to four months for each one, in one case of PAP diagnosed at the age of four months. CT scan findings at control were stable in the second PAP case.

We can say that, when performed for diagnosis purposes, FB led to (or contributed to elaborating) a specific diagnosis or excluded others in 255 cases $(74.8 \%)$. The degree of its contribution varied according to FB indications. It was effective in "foreign body suspicion", "ETF", "loculated recurrent pneumonia" and "stridor and bronchopulmonary malformations" groups. It was limited in "bronchiectasis" and "hemoptysis" groups. The BAL result was determinant in 86 cases $(43.9 \%)$. The FB findings influenced the management of the patients in 198 cases (58\%). The FB performed for therapeutic purposes was beneficial in all cases.

Complications occurred in $20 \mathrm{FB}(5.5 \%)$. It was minor in six cases (a slight desaturation) and major in 14 cases (deep desaturation under $90 \%(\mathrm{n}=12)$, convulsion ( $\mathrm{n}$ $=1)$, abundant epistaxis $(\mathrm{n}=1)$. The 12 patients presenting with deep desaturation during or immediately after the FB were under one year in half the cases and had a severe respiratory disease in all cases. Three of them had BAL. However, the major cause of that complication was the mechanical ventilation interruption during the FB. Because of fasting, antiepileptic therapy was not administered in one case inducing convulsion.

\section{Discussion}

FB is an integral part of the exploration of acute or chronic respiratory diseases in children. In our study, the FB for diagnostic purposes was of great diagnostic value in $74.8 \%$ of the cases. The major benefit was observed in the group "foreign body suspicion", "ETF", "loculated recurrent pneumonia" and "stridor and bronchopulmonary malformations". The FB contribution was poor in the "bronchiectasis" group probably because of the absence of electron microscopy study of the ciliary samples. On the other hand, the BAL for diagnosis purposes was beneficial in $43.9 \%$ of the cases. All these exams have modulated the subsequent management of the patients in $58 \%$ of the cases. The FB for therapeutic purposes was beneficial in all cases. Complications were rare $(5.5 \%)$, mainly explained by the clinical presentation and the absence of a parallel sufficient ventilation. The risk/benefit ratio should be better assessed before performing a FB in patients with high oxygen supplies.

In 2001, the French pediatric pulmonology group had evaluated the FB practice in children in France ${ }^{5}$. A total of $3886 \mathrm{FB}$ was realized during that year by 65 pediatric pulmonologists in 35 centers. The activity average per center was $116 \mathrm{FB}$ per year range, 6; 360]. Of the 35 centers, ten $(29 \%)$ were performing less than $50 \mathrm{FB}$ per year, $12(34 \%)$ between 50 and $100 \mathrm{FB}$ per year, and $13(37 \%)$ more than $100 \mathrm{FB}$ per year. Fifteen centers carried out FB in a surgical operating room, 13 in a dedicated room, and seven in a shared room with gastric endoscopy.

Conscious sedation respects the spontaneous breathing of the child, an essential parameter to detect tracheal dyskinesia $^{6}$. General anesthesia has the advantage of the child's and the operator's comfort, but it requires a careful monitoring in an operating room ${ }^{7}$. The final choice of the anesthetic mode remains a joint decision between the operator and the anesthetist. In France, FB was systematically carried out under general anesthesia in 18 centers among the 35 . Six centers could perform FB in both anesthesia modes with a preference for the conscious one. Eleven centers proceeded with conscious anesthesia 5 . In our study, the patients had conscious sedation more frequently than deep sedation because there was no permanent anesthetist assigned to our pediatric bronchoscopy unit.

FB and endoscopic sampling can confirm or decline several diagnoses but their contribution varies according to their indications, consisting mostly in bronchopulmonary chronic or recurrent symptoms or in searching an obstacle or an abnormal airway anatomy ${ }^{4,8-10}$. In an Indian pediatric series on $529 \mathrm{FB}, 284$ (53.6\%) were abnormal. FB was primarily motivated by RPI, persistent atelectasis and congenital stridor. It was abnormal in all cases of suspected pulmonary agenesis or ETF, in $88 \%$ of the cystic fibrosis cases, $79 \%$ of the stridor cases, $76 \%$ of the hemoptysis cases, and in $60 \%$ of the RPI 
cases. The BAL, performed in 469 patients, isolated a pathogen in $23 \%$ of the cases ${ }^{11}$. Barbato et $\mathrm{al}^{8}$ published a survey on the bronchoscopy practice in children in 51 European centers. In one year, 7446 bronchoscopies were performed of which 4587 were $\mathrm{FB}$. The main FB indications were RPI (17\%), poorly controlled asth$\mathrm{ma}(15.5 \%)$, persistent atelectasis $(14.3 \%)$, and stridor $(13.3 \%)$. The highest FB yield was found in the "stridor" group (81\%). Besides the diagnostic yield, FB guides therapeutic management. It was ascertained in our series and in Carroll et al's ${ }^{9}$ retrospective study of 180 pediatric FB (58\% and 51\%, respectively).

The BAL microbiological contribution is well established ${ }^{3,12}$. In a recent prospective study of 56 children with non-cystic fibrosis bronchiectasis, FB and BAL have contributed to changing the therapeutic management in 25 cases $^{13}$. However, although FB helps assess the airways disease in pulmonary tuberculosis ${ }^{14,15}$, the BAL yield is limited.

In a 255 children's BAL analysis, the acid-fast bacilli microscopy sensitivity and Mycobacterium tuberculosis culture was $8.4 \%$ and $28.9 \%$ respectively ${ }^{16}$. On the other hand, the BAL plays a major role in the interstitial lung disease diagnosis in children ${ }^{17}$. It is also the mainstay of the PAP treatment. In our study, the therapeutic BAL cured the disease in one case and stabilized it in the other. Over a period of nine years, Badiozaman et al ${ }^{18}$ performed 18 therapeutic BAL in nine children with PAP. The first BAL was performed after 20 months of evolution on average. Five children were healed.

Complications can occur immediately after the fiber-optic bronchoscope introduction as it interferes with basic respiratory physiological phenomena ${ }^{19}$. According to the Spanish recommendations ${ }^{10}$, they depend on risk factors related to the patient, anesthesia procedures, inappropriate choice of the endoscope size, and the operator's experience. The main complications are epistaxis, desaturation, cough, bronchospasm, an increase of tracheobronchial obstruction, hemorrhage, fever, and infection. De Blic et $\mathrm{al}^{20}$ examined the complications of 1328 pediatric FB. At least one complication was found in 91 cases $(6.9 \%)$. The most frequent minor complication was isolated excessive coughing $(\mathrm{n}=22)$.

Major complications were rare $(1.7 \%)$ including first an isolated desaturation under $90 \%(\mathrm{n}=21)$. They were associated with age under two years and laryngotrache- al abnormalities. Fever was observed remotely after a BAL in 52 cases out of 277 (18.8\%). Another prospective study of 91 pediatric FB recorded a significant association between fever within 24 hours post-FB and positive BAL culture ${ }^{21}$.

Although FB is a very useful tool, it is less efficient and less secure than rigid bronchoscopy in removing bronchial foreign bodies in children as compared to adults $^{22,23}$.

However, the rigid bronchoscopy remains an invasive procedure. Therefore, it is not recommended for the initial investigation. Righini et $\mathrm{al}^{23}$ conducted a prospective study in 70 patients with suspected foreign-body aspiration. Nineteen patients had undergone FB first and 51 rigid bronchoscopy first. The foreign body was found in seven cases in the first group, against 43 in the second group. The authors suggested rigid bronchoscopy prior to $\mathrm{FB}$ only in case of asphyxia, a radiopaque foreign-body, or an association of localized decreased breath sounds or wheezing, and emphysema or atelectasis. In our study, FB was performed for children with a doubtful penetration syndrome, atelectasis and/or localized emphysema.

The FB also shows limits in exploring narrow airways or in case of massive hemoptysis. Virtual bronchoscopy is a 3-dimensional noninvasive technique allowing viewing the intraluminal tracheobronchial tree. It has the advantage of evaluating the downstream areas of tight strictures, not crossable by the endoscope. However, it cannot detect mucosal lesions, airway malacia, or perform sampling ${ }^{24,25}$. In a series including 45 children, the virtual bronchoscopy confirmed $\mathrm{FB}$ abnormalities in 33 patients out of 38 and failed to detect a trachea-bronchial malacia in five cases. The sensitivity and specificity of the virtual bronchoscopy were respectively $86.6 \%$ and $85.7 \%{ }^{26}$.

\section{Conclusion}

The establishment of our FB unit has helped develop a better diagnostic and therapeutic approach to several respiratory diseases. FB offers more benefits than the rigid bronchoscopy and the virtual endoscopy in children. It is usually safe. To minimize its complications, the FB indications should be carefully analyzed as well as the patient's clinical status and the appropriate anesthesia choice.

\section{Source of support:}

Nil 


\section{Conflict of Interest:}

None declared.

\section{References}

1. Wood RE, Fink RJ. Applications of flexible fiber-optic bronchoscopes in infants and children. Chest. 1978;8:168-171.

2. Cakir E, Ersu RH, Uyan ZS, Oktem S, Karadag B, Yapar $\mathrm{O}$ et al. Flexible bronchoscopy as a valuable tool in the evaluation of persistent wheezing in children. Int J Pediatr Otorbinolaryngol. 2009;73(12):1666-8.

3. Radhakrishnan D, Yamashita C, Gillio-Meina C, Fraser DD. Translational research in pediatrics III: bronchoalveolar lavage. Pediatrics. 2014;134:135-54.

4. Kut A, Cakir E, Gokdemir Y, Midyat L, Ersu R, Erdem $\mathrm{E}$ et al. Intrinsic endobronchial obstructions in children from Turkey: evaluation of 2,555 flexible bronchoscopic procedures. Respiration. 2013;85:43-8.

5. Le Roux P, De Blic J, Albertini M, Bellon G, Body $\mathrm{G}$, Brémont $\mathrm{F}$ et al. Flexible bronchoscopy in children. Experience at French centers of pediatric pneumology. Rev Mal Respir. 2004 ; 21 :1098-106.

6. Jaggar SI, Haxby E. Sedation, anaesthesia and monitoring for bronchoscopy. Paediatr Respir Rev. 2002;3:3217.

7. Chen L, Yu L, Fan Y, Manyande A. A comparison between total intravenous anaesthesia using propofol plus remifentanil and volatile induction/ maintenance of anaesthesia using sevoflurane in children undergoing flexible fibreoptic bronchoscopy. Anaesth Intensive Care. 2013;41:742-9.

8. Barbato A, Magarotto M, Crivellaro M, Novello AJ, Cracco A, De Blic J et al. Use of the paediatric bronchoscope, flexible and rigid, in 51 European centres. Eur Respir J. 1997;10:1761-6.

9. Carroll C, Slattery DM. Paediatric flexible bronchoscopy and its indications. Ir Med J. 2010;103:305-7.

10. Pérez-Frías J, Moreno Galdó A, Pérez Ruiz E, Barrio Gómez De Agüero MI, Escribano Montaner A, Caro Aguilera P. Pediatric Bronchoscopy Guidelines. Arch Broncopneumol. 2011;47:350-360.

11. Kabra SK, Lodha R, Ramesh P, Sarthi M. Fiber-optic Bronchoscopy in Children: An Audit from a Tertiary Care Center. Indian Pediatr. 2008;45:917-9.

12. Wurzel DF, Marchant JM, Clark JE, Masters IB, Yerkovich ST, Upham JW, et al. Wet cough in children: infective and inflammatory characteristics in broncho-alveolar lavage fluid. Pediatr Pulmonol. 2014;49(6):561-8.

13. Pizzutto SJ, Grimwood K, Bauert P, Schutz KL, Yerkovich ST, Upham JW et al. Bronchoscopy contributes to the clinical management of indigenous children newly diagnosed with bronchiectasis. Pediatr Pulmonol. 2013:48;67-73.

14. Goussard P, Gie R. The role of bronchoscopy in the diagnosis and management of pediatric pulmonary tuberculosis. Expert Rev Respir Med. 2014;8:101-9.

15. Cakir E, Uyan ZS, Oktem S, Karakoc F. Flexible bronchoscopy for diagnosis and follow up of childhood endobronchial tuberculosis. Pediatr Infect Dis J. 2008;27(9):783-7.

16. Yin QQ, Jiao WW, Han R, Jiao AX, Sun L, Tian JL et al. Rapid diagnosis of childhood pulmonary tuberculosis by Xpert MTB/RIF assay using bronchoalveolar lavage fluid. Biomed Res Int. 2014;2014:310194.

17. Bush A, Cunningham S, de Blic J, Barbato A, Clement A, Epaud R et al. European protocols for the diagnosis and initial treatment of interstitial lung disease in children. Thorax. 2015 in press

18. Badiozaman R, Tahereh P, Shideh D, Mohammadreza B, Ahmadreza A, Seyyedahmad T. Whole Lung Lavage of Nine Children with Pulmonary Alveolar Proteinosis: Experience in a Tertiary Lung Center. Iran J Pediatr. 2013;23(1): 95-99.

19. Koumbourlis AC. Role of bronchoscopy in the intensive care unit. Paediatr Respir Rev. 2011;12:1-66.

20. De Blic J, Marchac V, Scheinmann P. Complications of flexible bronchoscopy in children: prospective study of 1,328 procedures. Eur Respir J. 2002;20:1271-6.

21. Picard E, Schwartz S, Goldberg S, Glick T, Villa Y, Kerem E. A prospective study of fever and bacteremia after flexible fiber-optic bronchoscopy in children. Chest. 2000;117:573-7.

22. Goyal R, Nayar S, Gogia P, Garg M. Extraction of tracheobronchial foreign bodies in children and adults with rigid and flexible bronchoscopy. J Bronchology Interv Pulmonol. $2012 ; 19: 35-43$.

23. Righini CA, Morel N, Karkas A, Reyt E, Ferretti K, Pin I et al. What is the diagnostic value of flexible bronchoscopy in the initial investigation of children with suspected foreign body aspiration? Int J Pediatr Otorbinolaryngol. 2007; 71:1383-90.

24. Adali F, Uysal A, Bayramoglu S, Guner NT, Yilmaz G. Virtual and fiber-optic bronchoscopy in patients with indication for tracheobronchial evaluation. Ann Thorac Med. 2010;5:104-109.

25. Muzaffar A, Dweik RA. Future of flexible bronchoscopy flexible bronchoscopy in the $21^{\text {st }}$ century. 1999;20:1.

26. Heyer CM, Nuesslein TG, Jung D, Peters SA, Lemburg SP. Tracheobronchial anomalies and stenoses: detection with low-dose multidetector CT with virtual tracheobronchoscopy-comparison with flexible tracheobronchoscopy. Radiology. 2007;242:542-9. 